\title{
Temporal variation in the population of bulbuls (Family Pycnonotidae) in lower montane forest, Northern Thailand
}

\author{
YUWADEE PONPITUK ${ }^{1}$, SUPALAK SIRI ${ }^{1,3}$, MONGKOL SAFOOWONG $^{2}$, WARONG SUKSAVATE ${ }^{1}$, \\ DOKRAK MAROD ${ }^{1,3}$, PRATEEP DUENGKAE ${ }^{1,3, \bullet}$ \\ ${ }^{1}$ Special Research Unit for Wildlife Genomics, Department of Forest Biology, Faculty of Forestry, Kasetsart University. 50 Ngamwongwan Rd., \\ Chatuchak, Bangkok 10900, Thailand. Tel.: +66-2-579-0176, Fax.: +66-2942-8107, `email: prateep.du@ku.ac.th \\ ${ }^{2}$ Deparment of National Park, Wildlife and Plant Conservation, Doi Chiang Dao Wildlife Research Station, Wildlife Research Division, Wildlife \\ Conservation Bureau, Chiang Mai, Thailand \\ ${ }^{3}$ Centre of Advanced Studies in Tropical Natural Resources, Kasetsart University, Bangkok 10900, Thailand
}

Manuscript received: 27 April 2020. Revision accepted: 20 July 2020.

\begin{abstract}
Ponpituk Y, Siri S, Safoowong M, Suksavate W, Marod D, Duengkae P. 2020. Temporal variation in the population of bulbuls (Family Pycnonotidae) in lower montane forest, Northern Thailand. Biodiversitas 21: 3644-3649. Temporal variations in the population of bulbuls (Family Pycnonotidae) were studied over the course of four years in a 16-ha lower montane permanent plot, Northern Thailand. This study aimed to determine the relationship of the temporal variation of forest gaps with the population size of the bulbul, which plays a crucial role in seed dispersal and insect control in tropical forest ecosystems. This long-term monitoring study in a permanent plot was conducted monthly from January 2016 through October 2019. Data were collected using the mist-netting method for the capture-recapture protocol with individual bird banding. A total of 33,120 traps hour for 46 months, 180 traps hour per day and 720 traps hour per month were recorded. The banding of a total of 94 individual bulbuls resulted in their classification into 5 species, consisting of Puff-throated Bulbul (Alophoixus pallidus), Mountain Bulbul (Ixos mcclellandii), Black-crested Bulbul (Pycnonotus flaviventris), Ashy Bulbul (Hemixos flavala) and Flavescent Bulbul (Iole virescens). The annual average density of bulbul for four years tended to decrease, but the difference was not significant. The highest average population occurred in 2016 and the lowest in 2018 with the changes being attributable to forest gap. Over time, monthly detection of bulbuls decreased gradually under closed canopy conditions, while in forest gaps, bird detection remained constant. As gap conditions so did detection probabilities. Our findings suggest that natural forest gaps can play an essential role as a temporal inhibitor to the rapid bird population decrease in the lower montane forest. This study will be useful for bird conservation and in balancing ecosystems for sustainability and providing interest in conservation initiatives requiring spatially explicit estimates of density.
\end{abstract}

Keywords: Bulbul, capture-recapture, mist-netting, permanent plot, population, variation

\section{INTRODUCTION}

The Bulbuls (Family Pycnonotidae) are a particularly important frugivorous group and are known for their important role in seed dispersal in the Asian region, especially in degraded habitat (Corlett 2017; Shakya and Sheldon 2017; Sankamethawee et al. 2011). Bulbuls are a generalist frugivore that is more flexible in its feeding habits with the ability to feed on many plant species (Wang et al. 2005; Sankamethawee et al. 2011; Menke et al. 2012; Kerdkaew et al. 2014). Bulbuls can be effective seed dispersers since they remove fruits, swallow them, and move away from the tree they feed on to defecate somewhere far away (Corlett 2017). Bulbuls tend to move further between subsequent feeding trees when food is scarce or more dispersed.

Species in the Family Pycnonotidae are an important component of tropical rainforest ecosystems and often exhibit differences associated with vegetation structure and composition. They are ecologically diverse and occupy a wide array of habitats. Bird species depend on the vegetation structure and composition (such as trees, shrubs, and herbs) and food resources for their survival and reproduction and are sensitive to habitat alteration (Zakaria et al. 2016). Therefore, the study monitoring the population of bulbul birds in the long-term fits nicely with known changes in forest ecology.

Climate change affects avian populations in different ways. In the lowland forest, the abundance of frugivores increased during La Niña years, but El Niño years did not have a significant effect on frugivore abundance. In this montane forest, the abundance increased consistently for all frugivorous birds during El Niño events, but their abundance decreased during La Niña (Barrantes and Sandoval 2019). In Northern Thailand, a study on El Niño and La Niña was conducted (Duangdai and Likasiri 2015), but bird populations were not monitored. Furthermore, the Intermediate Disturbance Hypothesis (IDH) predicts that maximum diversity of a community will be obtained at an intermediate level of disturbance and minimum diversity will be the result of minimum and extreme levels of disturbance, such as the Knobbed Hornbill (Rhyticeros cassidix) appearing to be sensitive to moderate disturbance, with populations occurring at greatest density, as well as that of endemic frugivores and insectivores (Livera 2019; Martin and Blackburn 2010). 
Forest gaps are important sources of habitat diversity, structural complexity, and wildlife and plant species diversity (Tews et al. 2004). Forest gaps created by natural disturbances are a common element in forest dynamics. The gaps promote high biodiversity and provide alternative sites for utilization by understory birds (Siri et al. 2019). However, in natural forests, biodiversity probably increased shortly after gap creation and decreased with canopy closing, because gaps resemble the natural forest over time due to plant succession (Muscolo et al. 2014). Research on monitoring long-term populations of bulbul in the forest gaps in an evergreen forest ecosystem has not been conducted in Thailand, and there have been few studies of temporal variation in bulbul population density in lower montane forests in Thailand. Thus, this study monitors temporal variation in bulbul population density, seeking to assess how forest gaps may influence bulbul population density in lower montane forest ecosystems in Thailand. This has important applications for bulbul conservation, helping us to understand how to manage lower montane forest ecosystems in a sustainable way.

\section{MATERIALS AND METHODS}

\section{Study area}

The study was conducted on the 16 ha permanent plot of lower montane forest (LMF) in the Mae Sa-Kog Ma Biosphere Reserve (18 $54^{\prime} \mathrm{N}$ and $\left.98^{\circ} 54^{\prime} \mathrm{E}\right)$, in the Doi Suthep-Pui National Park in Northern Thailand (Rueangket et al. 2019) (Figure 1). The elevation range within the permanent plot is 1,250-1,540 meters above mean sea level, the lowest average rainfall is $10 \mathrm{~mm}$ in the dry season during November-April, whereas the mean rainfall in the wet season is $335.2 \mathrm{~mm}$ occurring during MayOctober. The mean temperature in the wet season is in the range $18.93-21.79^{\circ} \mathrm{C}$ and $14.79-22.35^{\circ} \mathrm{C}$ in the dry season (Glomvinya et al. 2016; Pimrat 2016). This LMF has 219 plant species that occur in the Kog Ma Biosphere Reserve, with a top canopy height of $40 \mathrm{~m}$. Lauraceae is the dominant family (Marod et al. 2014). The diversity of the 211 species of wildlife is comprised of 30 species of mammals, 134 species of birds, 16 species of amphibians, and 31 species of reptiles (Duengkae et al. 2020).

\section{Data collection and analysis}

Bird surveys in each vegetation type were conducted using mist-netting following the technique previously used by Siri et al. 2019; Siri et al. 2020. Mist netting of understory birds was conducted in twelve sites. Net mesh (36 $\mathrm{m}$ in length, $9 \mathrm{~m}$ in height) was used to capture understory birds under closed canopies (CC) and forest gaps (FG). The center of each net site was recorded using a Global Position System (GPS) from January 2016 through October 2019. The twelve sites randomly selected for sampling were in the range of 200-600 $\mathrm{m}^{2}$. The mist nets were set monthly. Nets were opened for fore 4 sites per day with three consecutive days. The nets were opened at 06:00 $\mathrm{h}$ and closed at 16:00 h. Nets were checked every $30 \mathrm{~min}$ (Wunderle et al. 2005; Werema 2015; Siri et al. 2019). Each captured bird was banded with a numbered aluminum ring on the right tarsus before being released. All mistnetted birds were ringed and then released at the capture points; activities complied with the protocols of the Department of National Parks, Wildlife and Plant Conservation of Thailand, which granted permission (no. DNP 0907.4/9819) for our research. After banding, all birds were immediately released at the capture site to minimize the disruption of their normal movements. Time, location, species, and ring code (for recaptured birds) were recorded.

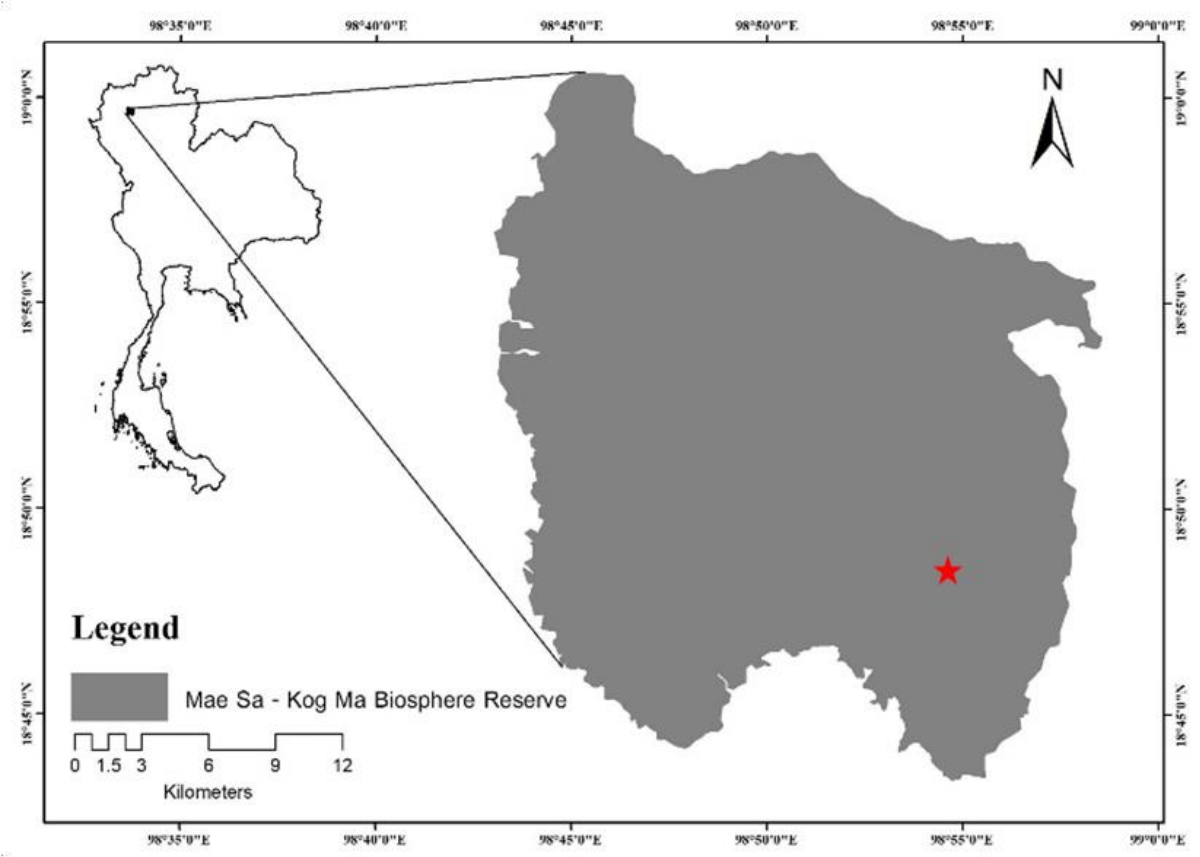

Figure 1. Location of the 16 ha permanent plot (red star) in the Mae Sa-Kog Ma Biosphere Reserve, Thailand 
Differences between sampling sessions and occasions in the two sites sampled, were accounted for by installing a series of competing models that included session and site effects to explain variation in density (D), baseline detection probability $\left(\mathrm{p}_{0}\right)$, and spatial scale parameter $(\sigma)$. To account for temporal variation in surface activity, we included the linear and quadratic effect of 'day of survey' as covariates on detectability. The association between detection probability and site parameters according to the gap, occasions, and their interaction were analyzed in $\mathrm{R}(\mathrm{R}$ Core Team 2019) using the package oSCR (Sutherland et al. 2019). Model selection, due to relatively small sample sizes was conducted using AIC-based model selection following Arnold (Arnold 2010). These models reduce biases in estimates of population density by accounting for forest gap and closed canopy conditions in detection probability.

\section{RESULTS AND DISCUSSION}

We recorded a total of 33,120 trap hours for 46 months, 180 trap hours per day and 720 trap hours per month in CC and FG locations. Of the total 94 individual birds captured, in 5 species, there were 46 individuals in $\mathrm{CC}$ sites and 48 individuals that were caught in FG sites. They consisted of, of 53 Puff-throated Bulbul (Alophoixus pallidus), 33 Mountain Bulbul (Ixos mcclellandii), 4 Blackcrested Bulbul (Pycnonotus flaviventris), 3 Ashy Bulbul (Hemixos flavala) and 1 Flavescent Bulbul (Iole virescens).

The study found that the annual average bulbul density for four years tended to decrease, although the difference was not significant $(p>0.05)$ (Table 1). The highest average was in 2016 (mean $\pm \mathrm{SE}$ ), at $16.64 \pm 4.69$ individuals/ha and lowest was in 2018 , at is $9.67 \pm 3.00$ individuals/ha (Figure 2). In the oSCR program, it was found that the best model (based on lower AIC) was more supportive of constant density across sites than between site variability (cumulative model weights $=0.065$ Table 2). The AIC-based model indicates that the most influential factors affecting the population were occasion (occas) and gap age (gap).

Based on 46 monthly data points, the detection probability between $\mathrm{CC}$ and FG is shown in Figure 3. Detection probability decreased gradually in $\mathrm{CC}$ while in FG held constant. Based on figure 3, we found that in the $\mathrm{CC}$, the detection probability was higher than in the FG and decreased until it was equal to the FG in the 18th month, then continuously decreased and was less than FG until the end of the study (Figure 3).

From the boxplot (Figure 4), the probability of detection of bulbuls over a period of 46 months in this study found that $\mathrm{CC}$ and FG were approximately 0.0014084 and 0.001480 . When compared, it was found that in $\mathrm{CC}$ there was high temporal variation, with the highest to 0.00245 and the lowest to 0.00070 while in FG there was low temporal variation, with the highest to 0.00154 and the lowest to 0.00141 . Density was equal to $\exp (\mathrm{d} 0)$. Therefore, $\exp (0.0014)$ was equal to 1.0014 individual/ha. The temporal variation in the population of bulbuls calculation showed that there were no significant differences between CC and FG. From monitoring FG in the study area, we know that FG can help slow down the population decline of bulbuls. The FG that is less than 18 months old plays an important role in forest ecology, helping to maintain the complex structure to preserve biodiversity, especially the density of bulbuls to rapidly increase.

Table 1. Regression coefficients of the top model describing the variability in density (D), baseline detection $\left(\mathrm{p}_{0}\right)$, and space use $(\sigma)$ of the bulbul as a function of site, session, and time

\begin{tabular}{lccc}
\hline Parameter & Estimate & SE & $\mathbf{P}(>|\mathbf{z}|)$ \\
\hline p. (Intercept) & -5.980 & 0.318 & 0.000 \\
t.beta.occas & -0.028 & 0.009 & 0.003 \\
t.beta.gap & -0.489 & 0.326 & 0.134 \\
t.beta.occas:gap & 0.026 & 0.013 & 0.049 \\
p.behav & 1.069 & 0.420 & 0.011 \\
sig. (Intercept) & 4.907 & 0.154 & 0.000 \\
d0. (Intercept) & 0.290 & 0.154 & 0.059 \\
\hline
\end{tabular}

Table 2. Variability in density $(D)$, baseline detection $\left(p_{0}\right)$ of the bulbuls as a function gap occasion and session for the population in a permanent plot of lower montane forest (LMF) all captures and observations are summed as two sites in the Mae Sa-Kog Ma Biosphere Reserve in the Doi Suthep-Pui National Park in Northern Thailand

\begin{tabular}{|c|c|c|c|c|c|c|}
\hline Detection (po) & $\begin{array}{c}\text { Log } \\
\text { likelihood }\end{array}$ & $\mathbf{K}$ & AIC & $\Delta_{\mathrm{AIC}}$ & Weight & CumWt \\
\hline $\mathrm{D}(-1)$ p( occas + gap + b occas:gap) sig (-1) & 665.6632 & 7 & 1345.326 & 0 & 0.064575 & 0.064575 \\
\hline $\mathrm{D}(-1) \mathrm{p}(-\mathrm{gap}+$ occas + b gap:occas) sig $(-1)$ & 665.6632 & 7 & 1345.326 & $9.78 \mathrm{E}-12$ & 0.064575 & 0.12915 \\
\hline $\mathrm{D}(-1)$ p(gap + occas + b gap:occas) sig $(-1)$ & 665.6632 & 7 & 1345.326 & $9.78 \mathrm{E}-12$ & 0.064575 & 0.193725 \\
\hline$D(-1)$ p(gap + occas + b gap:occas) sig $(-1)$ & 665.6632 & 7 & 1345.326 & $9.78 \mathrm{E}-12$ & 0.064575 & 0.2583 \\
\hline $\mathrm{D}(-1) \mathrm{p}($ occas $+b) \operatorname{sig}(-1)$ & 667.6728 & 5 & 1345.346 & 0.019159 & 0.063959 & 0.322259 \\
\hline $\mathrm{D}(-1) \mathrm{p}$ (month + I (month^2) + gap + occas $+\mathrm{b}+$ gap:occas) $\operatorname{sig}(-1)$ & 663.95 & 9 & 1345.9 & 0.573732 & 0.048471 & 0.37073 \\
\hline $\mathrm{D}(-1) \mathrm{p}\left(\mathrm{gap}+\right.$ month $+\mathrm{I}\left(\right.$ month $\left.^{\wedge} 2\right)+$ occas $+\mathrm{b}+$ gap:occas) $\operatorname{sig}(-1)$ & 663.95 & 9 & 1345.9 & 0.573732 & 0.048471 & 0.419201 \\
\hline $\mathrm{D}(-1) \mathrm{p}($ month + occas $+\mathrm{I}($ month^2) + gap $+\mathrm{b}+$ occas:gap) $\operatorname{sig}(-1)$ & 663.95 & 9 & 1345.9 & 0.573732 & 0.048471 & 0.467671 \\
\hline $\mathrm{D}(-1) \mathrm{p}$ (gap + month + occas $+\mathrm{I}($ month^2) $+\mathrm{b}+$ gap:occas) $\operatorname{sig}(-1)$ & 663.95 & 9 & 1345.9 & 0.573732 & 0.048471 & 0.516142 \\
\hline
\end{tabular}




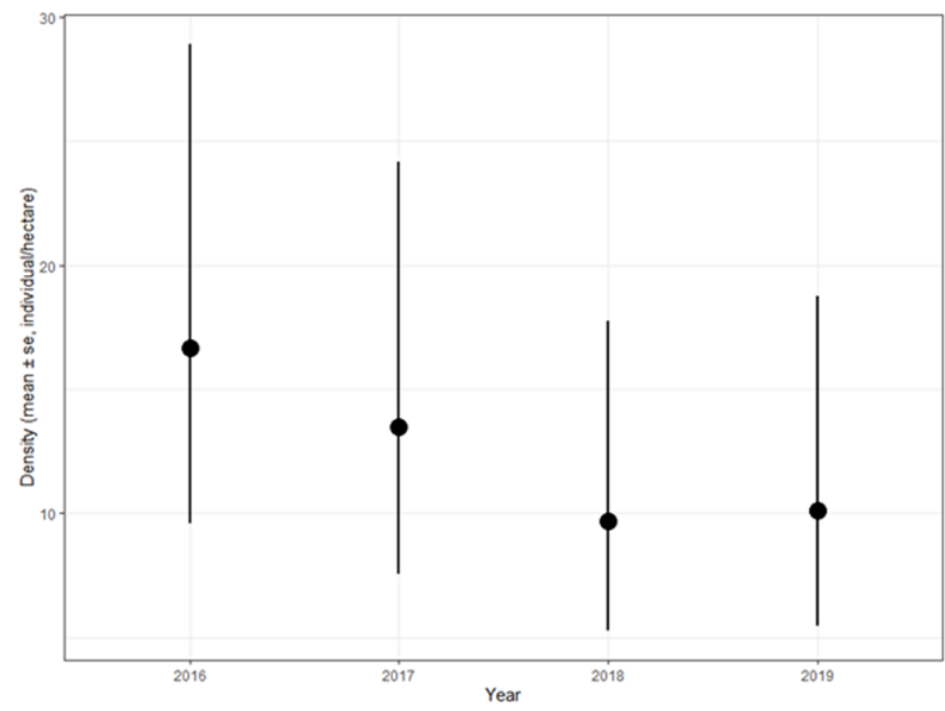

Figure 2. Temporal variation of the year and density of individuals per hectare

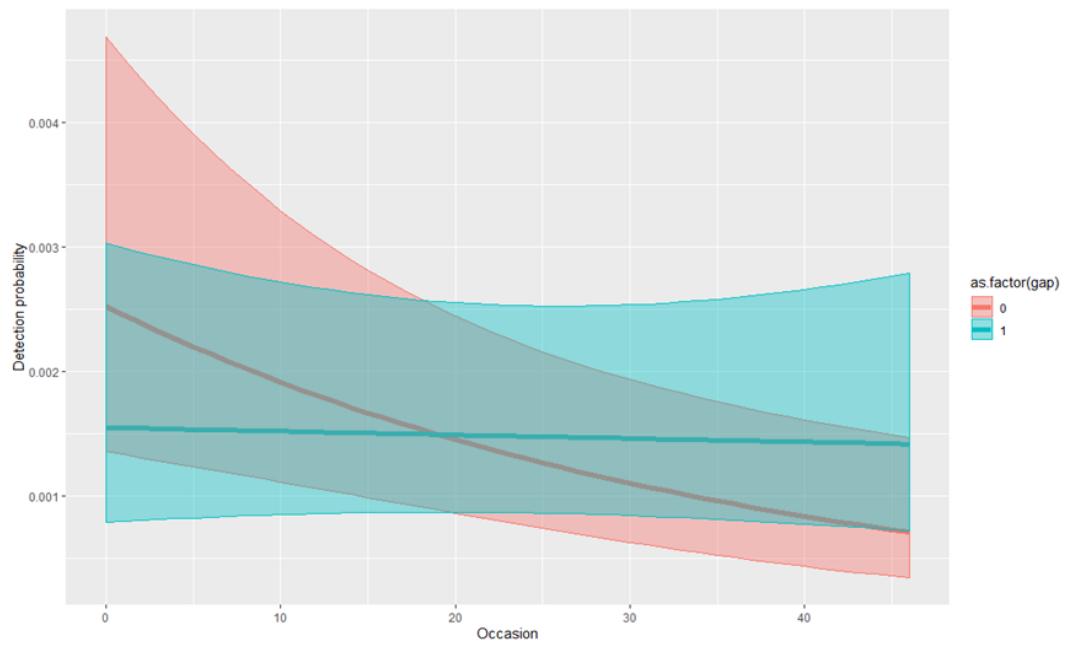

Figure 3. Monthly detection probability between closed canopy (0) and forest gaps (1) of bulbuls

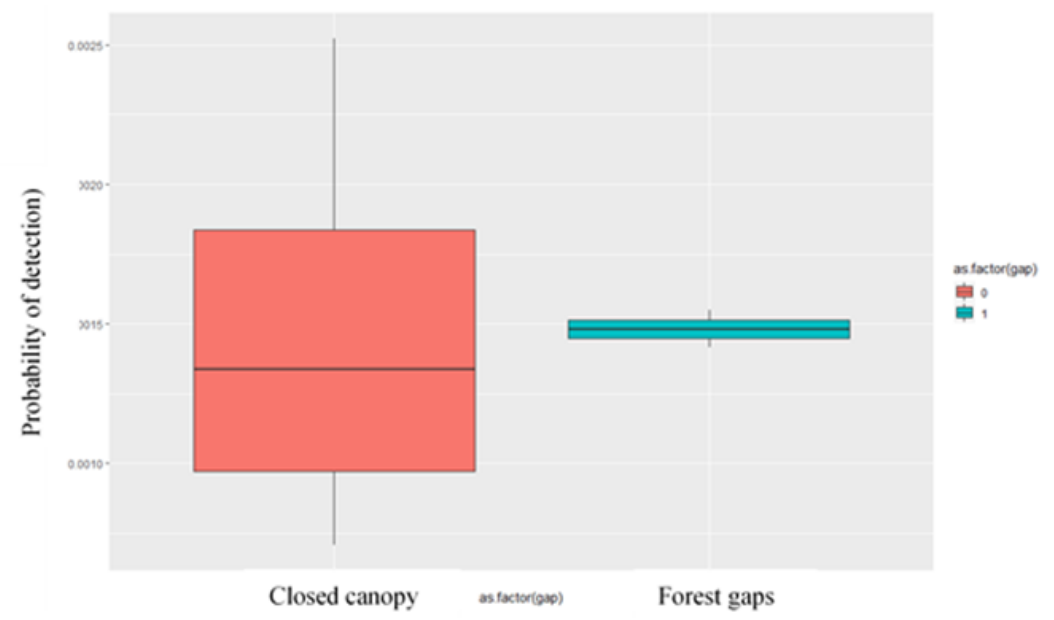

Figure 4. Variation of the population of bulbuls (n/ha) between closed canopy (0) and forest gaps (1) 


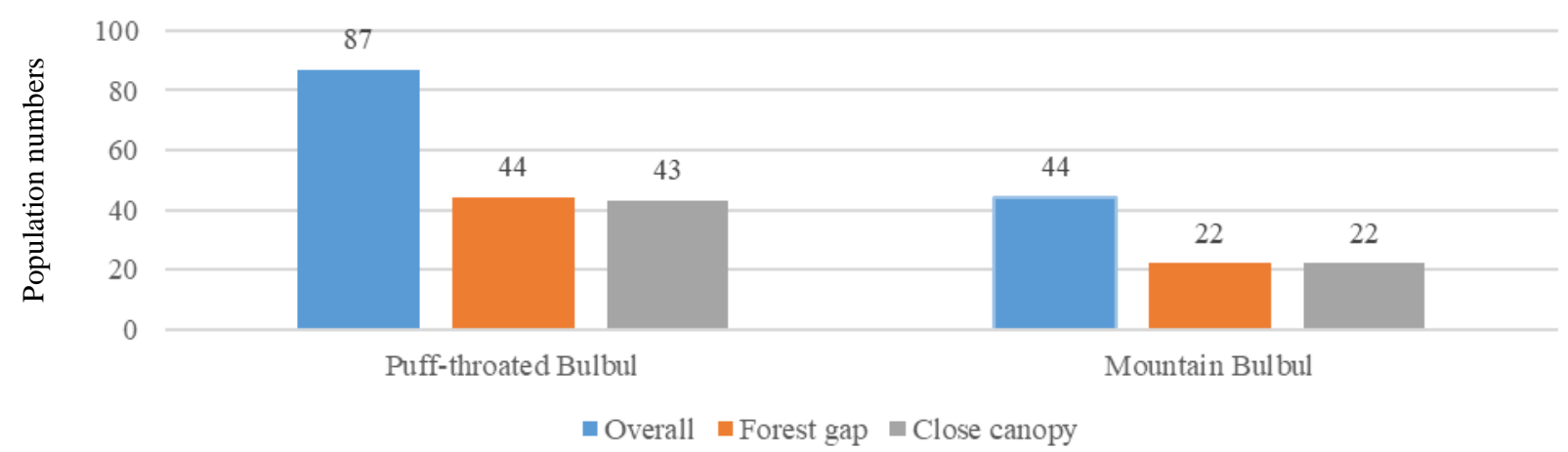

Figure 5. A comparison of population numbers between the Puff-throated Bulbul and the Mountain Bulbul in forest gap and closed canopy conditions

\section{Discussion}

The overall number of bulbul species that were detected is quite similar to that reported by Siri et al. (2013) in the Mae Sa -Kog Ma Biosphere Reserve, Northern Thailand. The current study showed that the population density of bulbuls in the lower montane forest, Northern Thailand, tended to decrease from 2016 during 2019 and averaged 16 individuals/ ha. These results differ from the previous report of Round et al. (2005), George et al. (2009), Sankamethawee et al. (2011) and Karin et al. (2015) that Black-crested Bulbul (Pycnonotus flaviventris) and Puffthroated Bulbul (Alophoixus pallidus) were 258.29 individual/ha and 211.61 individual/ha respectively. The differences in findings can be explained because the other studies used different methods for surveying, and study areas differed as well.

Two species of bulbuls that had high capture rates were the Puff-throated bulbul (Alophoixus pallidus) and Mountain bulbul (Ixos mcclellandii). We found that individual Puff-throated bulbuls were captured more than Mountain bulbuls, but overall, forest gap (FG) and closed canopy (CC) capture rates did not differ (Figure 5). Bulbuls are a generalist frugivore that is more flexible in their feeding habits on many plant species (Menke et al. 2012; Kerdkaew et al. 2014; Sankamethawee et al. 2011). From the individual recapture data of the Puff-throated bulbul, this species seemed to like to moves between CC and FG environments. The Puff-throated groups moved longer distances between fruiting trees when fruit abundance was lower and fruit dispersion higher (Korine et al. 2000, Khamcha et al. 2012), and the Mountain bulbul tended to move from CC to FG. This was similar to the findings of Khamcha and Gale (2012) who mentioned that Puffthroated Bulbuls used FG, with the frequency of gap use being significantly lower than expected. During the nonbreeding season, Puff-throated Bulbuls were detected in gaps much less than expected. Most of the detections in the gaps occurred during the breeding season.

We found that bulbuls under CC conditions had a decrease in numbers over time, while in the FG numbers were stable between years. Compared with Siri et al. (2019) in the same area, from the 5th month through the 12th month, cumulative species in the FG were higher than under CC conditions. In this study, the probability of population density of bulbul detection was higher in FG conditions than in CC, lasting as long as 28th months and continuously decreasing until the bulbul population was less than in FG until the end of the study. This occurred because natural ecological disturbance created habitats that are used by diverse groups of birds (Brawn et al. 2001). This is consistent with the Rosely et al. (2007) study concerning the effects of tree-fall gap areas and the association with bird distribution. The result was that birds detected in gap areas were significantly higher in number compared to the $\mathrm{CC}$ areas. Open conditions provided better foraging ground for various species, making this a better habitat for a wide range of species (Raman et al. 1998; Chettri et al. 2001)

The finding that the overall temporal variation density decreased may be supportive of the Intermediate Disturbance Hypothesis (IDH) following the previously mentioned study (Siri et al. 2019). In this study area annual rainfall and the mean temperature increased (Duangdai and Likasiri 2015; Hermhuk et al. 2019) and forest fires occurred with high frequency (Paansri et al. 2019). IDH explains that the maximum diversity of a community will be obtained at an intermediate level of disturbance, and minimum diversity will be the result within areas of both minimal and extreme levels of disturbance (Bongers et al. 2009). Our results generally support the IDH, because bulbuls are frugivorous birds that forage more frequently in gaps relative to the forest interior sites, presumably because the gaps provided greater fruit (as well as arthropod) resources (Khamcha and Gale 2012). The FG resulted in a diverse range of habitats and provided a window of opportunity for increasing the bird population, but as the FG filled in overtime, the bird population was again reduced.

\section{ACKNOWLEDGEMENTS}

We would like to thank the Department of National Parks and Wildlife and Plant Conservation, Mae Sa-Kog Ma Biosphere Reserve, Doi Suthep-Pui National Park, and Doi Chiang Dao Wildlife Reserve Station, Chiang Mai 
Province, Thailand for giving permission to conduct this study. We are grateful for all fieldwork assistance, particularly from Wachirapon Khumbucha, Niwat Intawin, Bunjerd Kiriya, Pongsit Srikhunmuang, Apisada Rueangket, Maratreenung Seehakrai, Nutthakarn Boonpha, Thansuda Dowwiangkan, Paanwaris Paansri, Apinya Saisamon and the other students at the Department of Forest Biology, Faculty of Forestry, Kasetsart University, Bangkok, Thailand for their support in the fieldwork.

\section{REFERENCES}

Arnold TW. 2010. Uninformative parameters and model selection using Akaike's Information Criterion. J Wildl Manag 74 (6): 1175-1178.

Barrantes G, Sandoval L. 2019. Effect of El Niño and La Niña on abundance of frugivorous and nectarivorous terrestrial birds in three tropical forests. Rev Biol Trop 67 (2): S282-S297.

Brawn JD, Robinson SK, Thompson III FR. 2001. The role of disturbance in the ecology and conservation of birds. Ann Rev Ecol Evol Syst 32 (1): 251-276

Bongers F, Poorter L, Hawthorne WD, Sheil D. 2009. The intermediate disturbance hypothesis applies to tropical forests, but disturbance contributes little to tree diversity. Ecol Lett 12 (8): 798-805.

Chettri N, Sharma E, Deb DC. 2001. Bird community structure along a trekking corridor of Sikkim Himalaya: a conservation perspective. Biol Conserv 102 (1): 1-16

Corlett RT. 2017. Frugivory and seed dispersal by vertebrates in tropical and subtropical Asia: an update. Global Ecol Conserv 11: 1-22.

Duangdai E, Likasiri C. 2015. Mathematical model analyses on the effects of global temperature and forest cover on seasonal rainfalls: A Northern Thailand case study. J Hydrol 524: 270-278.

Duengkae P, Marod D, Siri S, Ponpituk Y, Suksavate W, Paansri P, Chaiyes A. 2020. Ecological monitoring on wildlife in montane forest dynamics plot at Mae Sa-Kog Ma Biosphere Reserve. In: Marod D (ed.) Thai Forest Ecological Research Network Conference. Faculty of Forestry, Kasetsart University, Bangkok. [Thailand]

George GA, Round PD. Pierce AJ, Nimnuan S, Pattanavibool A, Brockelman WY. 2009. A field test of distance sampling methods for a tropical forest bird community. The Auk 126 (2): 439-448.

Glomvinya S, Tantasirin C, Tongdeenok P, Tanaka N. 2016. Changes in rainfall characteristics at Huai Kog-Ma Watershed, Chiang Mai province. Thai J For 35 (2): 66-77.

Hermhuk S, Chaiyes A, Thinkampheang S, Danrad N, Marod D. 2019. Land use and above-ground biomass changes in a mountain ecosystem, northern Thailand. J For Res 25 (2): 385-392.

Karin T, Thapong C, Radtha J, Safoowong M. 2015. Species diversity of bird in 25hectare permanent bird plot at Doi Chiangdao Wildlife research station, Chiang Mai Province. Wildlife Yearbook 15: 275 323. [Thailand]

Kerdkaew T, Gale GA, Bumrungsri S. 2014. Preliminary diet analysis reveals the dispersal of an exotic plant by two native Bulbuls in an early successional habitat, Krabi, Southern Thailand. Trop Nat Hist 14 (1): 35-42.

Korine C, Kalko EKV, Herre EA. 2000. Fruit characteristics and factors affecting fruit removal in a Panamanian community of strangler figs. Oecologia 123 (4): 560-568.

Khamcha D, Savini T, Brockleman WY, Chimchome V, Gale GA. 2012. Influence of food availability and distribution on the movement patterns of a forest avian frugivore, the puff-throated bulbul (Alophoixus pallidus). J Trop Ecol 28 (1): 1-9.

Khamcha D, Gale GA. 2012. The use of tree-fall gaps by a forest interior avian frugivore in a tropical evergreen forest. Forktail 28 (2012): 5356.

Livera L. 2019. Ecological Theory of Disturbance: Intermediate Disturbance Hypothesis. 3Rs in Ecology https://biol420eres525.wordpress.com.

Marod D, Sungkaew S, Duengkae P, Asanok L, Kamyo T, Hemhuk S, Pammongkol A, Thinkampaeng S. 2014. Plant diversity of lower montane evergreen forest at Huai Kogma watershed area, Doi Suthep-
Pui National Park, Chiang Mai province. In: Marod D, Thapyai C (eds) Thai Forest Ecological Research Network Conference. Faculty of Agriculture, Naresuan University, Phitsanulok. [Thailand]

Martin TE, Blackburn GA. 2010. Impacts of tropical forest disturbance upon avifauna on a small island with high endemism: implications for conservation. Conserv Soc 8 (2): 127-139.

Menke S, Böhning GK, Schleuning M. 2012. Plant-frugivore networks are less specialized and more robust at forest-farmland edges than in the interior of a tropical forest. Oikos 121 (10): 1553-1566.

Muscolo A, Bagnato S, Sidari M, Mercurio R. 2014. A review of the roles of forest canopy gaps. J For Res 25 (4): 725-736.

Paansri p, Suksavate W, Sir S, Ponpithuk Y, Safoowong M, Nuipakdee W, Maksin P, Ragsasilp A, Duengkae P. 2019. Abundance of Resident Birds--Responses to Environmental Factors at Mae Sa-Kog Ma Biosphere Reserve, Chiang Mai Province: A Case Study of Hill Blue Flycatcher (Cyornis banyumas). In: Waramit N (ed): of The $16^{\text {th }}$ National Kasetsart University Kamphaeng Saen Conference. [Thailand]

Pimrat M. 2016. Dynamics of Tree Seedlings Under Gap and Crown Canopy in Lower Montane Evergreen Forest at Doi Suthep-Pui National Park, Chiang Mai Province. [Dissertation]. Kasetsart University, Bangkok. [Thailand]

Raman TS, Rawat GS, Johnsingh AJT. 1998. Recovery of tropical rainforest avifauna in relation to vegetation succession following shifting cultivation in Mizoram, north-east India. J Appl Ecol 35 (2): 214-231.

R Core Team. 2019. R: A language and environment for statistical computing. R Foundation for Statistical Computing, Vienna, Austria.

Round PD, Gale GA, Pierce AJ, Pobprasert K, Sankamethavee W, Tokue K, Brockelman WY. 2005. Ecology of forest birds at Mo-Singto. In: Khao Yai Khon Kaen 10-13. [Thailand]

Rosely NFN, Sah SAM, Mashhor M. 2007. Avian distribution and diversity in forest gap and closed canopy areas of lowland tropical forest. J Biosci 18 (2): 57-75.

Rueangket A, Duengkae P, Thinkhampang S, Marod D. 2019. Utilization of fruit by frugivores in lower montane forest at Doi Suthep-Pui National Park, Chiang Mai province. Agr Nat Resour 53 (2019): 457464.

Sankamethawee W, Pierce AJ, Gale GA, Hardesty BD. 2011. Plant frugivore interaction in an intact tropical forest in north-east Thailand. Integr Zool 6 (3): 195-212.

Shakya SB, Sheldon FH. 2017. The phylogeny of the world's bulbuls (Pycnonotidae) inferred using a supermatrix approach. Ibis 159 (3): 498-509.

Siri S, Duengkae P, Marod D. 2013. Species diversity and abundance of birds in hill evergreen forest permanent plot at Huai Kok Ma, Chiang Mai Province. J Wild Thailand 20 (1): 97-112.

Siri S, Ponpithuk Y, Safoowong M, Marod D, Duenkae P. 2019. The natural forest gaps maintenance diversity of understory birds in Mae Sa-Kog Ma Biosphere Reserve, northern Thailand. Biodiversitas 20 (1): 181-189.

Siri S, Ponpituk Y, Safoowong M, Nuipakdee W, Marod D, Duengkae P. 2020. Comparing morphological traits of legs of understory birds inhabiting forest areas with closed canopies and forest gaps. Biodiversitas 21 (3): 1041-1048.

Sutherland C, Royle JA, Linden DW. 2019. oSCR: a spatial capturerecapture $\mathrm{R}$ package for inference about spatial ecological processes. Ecography 42 (9): 1459-1469.

Tews J, Brose U, Grimm V, Tielbörger K, Wichmann MC, Schwager M, Jeltsch F. 2004. Animal species diversity driven by habitat heterogeneity diversity: the importance of keystone structures. J Biogeogr 31 (1): 79-92.

Wang WY, Guo YS, Hu JC, Sun LH, Zhu L. 2005. Preliminary study on feeding and spatial niche of Pycnonotus sinensis in spring. J Zool 24: 466-468.

Werema C. 2015. Seasonal variation in understory bird species diversity and abundance in the Uluguru Nature Reserve, Tanzania. Anim Ecol 54 (3): 299-307.

Wunderle GM, Willig RMR, Henriques LMP. 2005. Avian distribution in tree-fall gap and understory of terra firme forest in the lowland Amazon. Ibis 147 (1): 109-129.

Zakaria M, Rajpar MN, Ozdemir I, Rosli Z. 2016. Fauna diversity in tropical rainforest: Threats from land-use change. Intech 2: 11-49. 